\title{
EL COMPORTAMIENTO ELECTORAL EN LAS ELECCIONES LOCALES DE 2015 EN EL ÁREA METROPOLITANA DE VALENCIA
}

\author{
Joaquín Martín Cubas \\ Anselm Bodoque Arriba \\ Pilar Rochina Garzón \\ Francisco Clemente González \\ Instituto Interuniversitario de Desarrollo Local \\ Universitat de València ${ }^{1}$ \\ Contacto: joaquin.martin@uv.es
}

Fecha de recepción: 10/09/2016

Fecha de aceptación: 10/01/2017

\begin{abstract}
Resumen
Las elecciones locales de 2015 pueden ser consideradas unas elecciones de crisis en las que el comportamiento electoral de los valencianos, en lo que se refiere cuanto menos al área metropolitana de Valencia, ha experimentado grandes cambios: por un lado, los dos partidos que tradicionalmente se repartían casi el $80 \%$ de los votos en el área, el PP y el PSPV-PSOE (71,94\% en las elecciones de 2011), han descendido drásticamente en votos hasta el punto de quedarse por debajo del $50 \%$ de los mismos (46, $94 \%$ de los votos en las elecciones de 2015), descenso que incluso ha afectado al tercer partido tradicionalmente en discordia que era, aun con un menor porcentaje de votos, EU (en torno al 5-7\% de los votos); mientras que, por otro lado, han surgido nuevas fuerzas políticas -Compromís, Ciudadanos y Podemos- con el suficiente empuje para disputar los primeros puestos del escalafón electoral a los dos grandes partidos: Compromís, 19,46\%; Ciudadanos, 10,70\%; y Podemos, sumando -con las reservas obvias para el caso-las candidaturas que se inspiran de una $u$ otra forma en sus planteamientos, $8,10 \%$. Con estos resultados se abre una nueva etapa en la historia electoral del área metropolitana de Valencia en la que el PP pierde su posición dominante y reaparece el antiguo cinturón rojo del área metropolitana de Valencia ahora con otros matices. En esta comunicación, por ello, queremos analizar, en primer lugar, la evolución del voto en el área desde las primeras elecciones locales de 1979 y el rendimiento institucional alcanzado; en segundo lugar, el comportamiento electoral en relación a cada uno de los partidos; para, en tercer lugar, desagregar el estudio de ese comportamiento por distintas variables como el tamaño del municipio, el comportamiento comarcal y, en concreto, el del cinturón rojo de Valencia; para, en cuarto lugar, extraer las oportunas conclusiones del análisis realizado
\end{abstract}

Palabras clave: Elecciones,, Comportamiento electoral,, Gobierno local, Área metropolitana,, Política local

\footnotetext{
${ }^{1}$ Este trabajo se ha realizado en el marco de los proyectos de investigación "Sostenibilidad y competitividad urbanas en un contexto global. El área metropolitana de Valencia (CSO2013-46863-C3-1-R) y Estructura social, encuestas y elecciones (CSO2013-43054-R) financiados por la convocatoria 2013-Proyectos I+D+IPrograma estatal de Investigación, Desarrollo e Innovación orientada a los retos de la Sociedad del Ministerio de Economía y Competitividad.
} 


\title{
ELECTORAL BEHAVIOR AT THE 2015 LOCAL ELECTIONS IN THE METROPOLITAN AREA OF VALENCIA
}

\begin{abstract}
Summary
Local elections in 2015 can be considered crisis elections in which the electoral behavior of the Valencians, in what refers at least to the metropolitan area of Valencia, has experienced major changes: on one hand, the two parties that traditionally distributed almost $80 \%$ of the votes in the area, the PP and the PSPV-PSOE (71.94\% in the 2011 elections), have fallen drastically in votes to the point of staying below $50 \%$ of them (46, $94 \%$ of the votes in the 2015 elections), descent that has even affected the third party traditionally in discord that was, even with a lower percentage of votes, EU (around 5-7\% of the votes); while, on the other hand, there have arisen new political forces -Compromís, Ciudadanos and Podemos- with enough drive to contest the top of the electoral ladder to the two major parties: Compromís, 19.46\%; Ciudadanos, 10.70\%; and Podemos, adding -with obvious reservations for the case- applications inspired by one way or another in their approaches, $8.10 \%$. The results opens a new stage in the electoral history of the metropolitan area of Valencia where the PP loses its dominant position and reappears the old red belt in the metropolitan area of Valencia now with other shades. In this paper, therefore, we want to analyze, firstly, the evolution of the vote in the area since the first local elections in 1979 and achieved institutional performance; secondly, the electoral behavior in relation to each of the parties; for, thirdly, analyze this behaviour according to different variables such as the size of the municipality, the regional behavior and, in particular, the red belt of Valencia; for, fourthly, draw the appropriate conclusions from the analysis.
\end{abstract}

Key words: Electoral Behavior, Elections, Local Government, Metropolitan Area, Local Politics.

\section{INTRODUCCIÓN.}

Las elecciones locales de 2015 pueden ser consideradas unas elecciones de crisis en las que el comportamiento electoral de los valencianos ha experimentado grandes cambios por lo que se refiere cuanto menos al área metropolitana de Valencia: por un lado, los dos partidos que tradicionalmente se repartían casi el $80 \%$ de los votos en el área, el PP y el PSPV-PSOE (2011: 71,94\%,) han descendido drásticamente en votos hasta el punto de quedarse por debajo del 50\% de los mismos (2015: 46, 94\%). Este descenso también ha afectado al tercer partido tradicionalmente en discordia, EU (5-7\%). Por otro lado, han surgido nuevas fuerzas políticas -Compromís, Ciudadanos y Podemos- con el suficiente empuje para disputar los primeros puestos del escalafón electoral a los dos grandes partidos: Compromís, 19,46\%; Ciudadanos, 10,70\%; y Podemos, sumando -con las reservas obvias para el caso- las candidaturas que se inspiran de una u otra forma en sus planteamientos, 8,10\%.

El apoyo electoral al PP, que venía in crescendo desde 1999 hasta alcanzar su pico en 2011 (46,11\% de los votos), ha caído en picado hasta reducir a la mitad sus apoyos $(25,56 \%)$ y perder la mayor parte de las alcaldías que ostentaba en la anterior legislatura. EI PSPV-PSOE, si bien ha recuperado buena parte del poder institucional en forma de alcaldías, sin embargo cuanto apenas ha mantenido los apoyos cosechados en los anteriores comicios. De hecho su apoyo se ha reducido de un 25,76\% a un 21,38\%. EU, con un nivel más reducido de apoyos, sin embargo ha experimentado un comportamiento electoral similar. Ha pasado de un $6,38 \%$ a un $5,64 \%$ de los votos. 
Por su lado, Compromís ha dado un salto cualitativo hasta el punto de estar en condiciones de pugnar con los dos grandes partidos por el primer puesto al sumar casi un $20 \%$ de los votos. La alianza del nacionalismo valenciano (Bloc) con una escisión de IU (Iniciativa) bajo el liderazgo mediático de Mónica Oltra, ha conseguido abrir un amplio hueco entre los votantes de izquierda y, en parte, de centro derecha. Ciudadanos, por su parte, ha aparecido en el escenario político valenciano con una fuerza inusitada al obtener más del $10 \%$ de los votos. En el ámbito ideológico del centro-derecha se presenta como alternativa creíble al otrora incuestionable PP. Finalmente, no menos sorprendente han sido los resultados electorales de Podemos, fuerza política inexistente en los anteriores comicios. Como Compromís ha pugnado por representar el espíritu de los indignados y del hartazgo con una forma de hacer política, alcanzando casi un $10 \%$ de los votos en el área metropolitana, si bien hay que reseñar las dificultades para medir sus apoyos al no presentarse como tal en las elecciones locales e integrarse sus militantes en listas electorales muy variadas y no uniformes.

Con estos resultados se abre una nueva etapa en la historia electoral del área metropolitana de Valencia; historia que ha estado marcada por cuatro hitos. En un primer momento, a partir de las primeras elecciones democráticas y durante los primeros años de la democracia (1979-1991), se consideró que este área era un bastión inexpugnable de la izquierda. Ya entonces, los municipios que rodeaban la ciudad de Valencia fueron conocidos como el cinturón rojo de Valencia, siguiendo el ejemplo de lo que sucedía en otras grandes ciudades. Esta peculiaridad se hizo aún más evidente tras las elecciones de 1991, el segundo gran hito de la historia electoral del área metropolitana, cuando la ciudad de Valencia pasó a estar gobernada por la derecha con cómodas mayorías; y, sin embargo, los municipios que rodean Valencia mantenían el apoyo tradicional a la izquierda. En las elecciones de 2011, tercer hito, el cinturón rojo se rindió también a la derecha y el PP pasó a controlar prácticamente todos los municipios del área metropolitana. Era el escalón final de una progresión continua de la derecha en forma de mancha de aceite que se había iniciado veinte años atrás. Parecía iniciarse un nuevo reinado esta vez conservador en este territorio.

Sin embargo, con las elecciones de mayo de 2015, cuarto hito, la realidad electoral del área ha dado un nuevo giro. La izquierda ha vuelto a salir victoriosa de la contienda electoral y esta vez no sólo en el cinturón rojo sino también en la ciudad de Valencia. Ahora bien, en esta ocasión además resulta novedoso el hecho de que no sea una única fuerza política la que protagonice la nueva situación electoral e institucional, sino que el predominio de la izquierda se sustenta ahora en una miríada fragmentada de partidos políticos (PSPV-PSOE, Compromís, Podemos, EU y otros partidos menores) que solos -en pocos casos- y coaligados -en la mayor parte- han formado los gobiernos de casi todos los municipios del área.

Más allá de las razones que explican este nuevo rumbo en el comportamiento electoral de los valencianos, para lo cual necesitaríamos estudios demoscópicos y cualitativos específicos, nuestro propósito en este artículo es analizar el comportamiento electoral del área metropolitana de Valencia en las elecciones locales con el objeto de caracterizarlo y entender las dinámicas del sistema de partidos en el área. En primer lugar, comenzaremos con un breve recorrido histórico a lo largo de las elecciones locales 
celebradas en las localidades del área metropolitana de Valencia. Comprobaremos cómo se produce la pérdida de votos y de ayuntamientos por parte de los partidos de izquierdas desde mediados de los noventa. Constataremos cómo esta caída se intensifica desde las elecciones de 2003, y con más fuerza en las elecciones de 2007 y 2011. Analizaremos, con más detenimiento y en función de distintos criterios territoriales, las elecciones locales de 2015 donde el cinturón rojo, que parecía haberse volatilizado, vuelve a resurgir. Con estas últimas elecciones parece que se abre una nueva etapa de mayor pluralismo y fragmentación en nuestro particular sistema de partidos, con nuevos actores políticos con una relevancia creciente en el área metropolitana de Valencia.

\section{2. ÁMBITO TERRITORIAL DE ANÁLISIS: EL ÁREA METROPOLITANA DE VALENCIA.}

Desde un punto de vista jurídico-institucional, las áreas metropolitanas fueron definidas por el artículo 43.2, de la Ley 7/1985, Reguladora de las Bases de Régimen Local, como "entidades locales integradas por los municipios de grandes aglomeraciones urbanas entre cuyos núcleos de población existían vinculaciones económicas y sociales que hagan necesaria la planificación conjunta y la coordinación de determinados servicios y obras". Sin embargo, dada la dificultad para definir estadísticamente este concepto, existen pocos estudios que tengan como marco de referencia el área metropolitana. Como afirman Antonio Montiel y Ernest García, "la falta de armonización de las definiciones a escala europea y la carencia de datos cuantitativos fiables limitan la ejecución y fiabilidad de comparaciones". El caso valenciano es un caso más particular donde la institucionalización metropolitana es casi inexistente debido a la resistencia de los diversos actores políticos y grupos de interés de la realidad valenciana.

Ahora bien, la delimitación en este estudio del área metropolitana de Valencia responde a una realidad social concreta, la de una red que se extiende en el territorio valenciano y que parte desde un núcleo definido, la ciudad de Valencia. Las localidades de su entorno comparten rasgos culturales, un sistema de integración socio-económico, una sólida red de transportes y carreteras, y un centro de gravedad político, aunque no institucional para la toma de decisiones. Se trata de "un sistema socio-espacial que emerge de la difusión a través del espacio de un asentamiento central" (Martínez y Martínez, 2002: 471-486). Nuestra hipótesis de trabajo es que Valencia sería ese núcleo central urbano que se expande diseminando sus características, las cuáles disminuyen su intensidad de forma paulatina a medida que se alejan de la capital, fenómeno cuya existencia también es constatable en su dimensión electoral.

Los criterios de delimitación utilizados serían los siguientes: las áreas metropolitanas quedan constituidas por un municipio central que cumple determinadas condiciones de tamaño demográfico, en este caso Valencia; y localidades adyacentes que están vinculados a él por niveles de relación residencia-trabajo: Más de 100.000 habitantes o entre 100.000 y 50.000, con una corona de al menos 50.000 habitantes. En referencia a la integración metropolitana: $20 \%$ de movilidad a o desde el municipio central/más de 100 trabajadores ó $15 \%$ de movilidad a o desde el municipio central/más de 100 trabajadores, para las localidades vinculados. El algoritmo utilizado sigue los 
criterios convencionales utilizados, adaptados a las condiciones específicas del sistema urbano español.

Conforme a la metodología aplicada en este trabajo, el área metropolitana de Valencia integraría a los setenta y seis municipios de la siguiente tabla:

Tabla 1: Municipios del área Metropolitana de Valencia

\begin{tabular}{|l|l|l|}
\hline ALAQUÀS & DOMEÑO & PICANYA \\
\hline ALBAL & ELIANA (L') & PICASSENT \\
\hline ALBALAT DELS SORELLS & EMPERADOR & POBLA DE FARNALS (LA) \\
\hline ALBORAYA & FAURA & PABLA DE VALLBNA (LA) \\
\hline ALBUIXECH & FOIOS & PUIG (EL) \\
\hline ALCÀSSER & GILET & PUÇOL \\
\hline ALDAIA & GODELLA & QUART DE POBLET \\
\hline ALFAFAR & GODELLETA & RAFELBUNYOL \\
\hline ALFARA DEL PATRIARCA & LLÍRIA & RIBA-ROJA DE TÚRIA \\
\hline ALGINET & LLOCNOU DE LA CORONA & ROCAFORT \\
\hline ALMÀSSERA & LORIGUILLA & SAGUNT \\
\hline ALMUSSAFES & MANISES & SAN ANT. DE BENAGÉBER \\
\hline BENAGUASIL & MARINES & SEDAVÍ \\
\hline BENETÚSSER & MASSALFASSAR & SERRA \\
\hline BENIFAIRÓ DE LES VALLS & MASSAMAGRELL & SILLA \\
\hline BENIFAIÓ & MASSANASSA & SOLLANA \\
\hline BENIPARRELL & MELIANA & TAVERNES BLANQUES \\
\hline BENISANÓ & MISLATA & TORRENT \\
\hline BÉTERA & MONCADA & TURÍS \\
\hline BONREPÒS I MIRAMBELL & MONTSERRAT & VALENCIA \\
\hline BURJASSOT & MUSEROS & VILAMARXANT \\
\hline CANET D'EN BERENGUER & NÁQUERA & VILLAR DEL ARZOBISPO \\
\hline CASINOS & OLOCAU & VINALESA \\
\hline CATARROJA & PAIPORTA & XIRIVELLA \\
\hline CHESTE & PATERNA & \\
\hline CHIVA & PETRÉS & \\
\hline & IOANA & \\
\hline
\end{tabular}

Fuente: Instituto Interuniversitario de Desarrollo Local

\section{EVOLUCIÓN DEL VOTO EN EL ÁREA METROPOLITANA DE VALENCIA (1979-2011).}

Las primeras elecciones locales de 1979 estuvieron marcadas por una elevada abstención: un $32,89 \%$ de los ciudadanos con derecho a voto no acudieron a las urnas. EI PSPV-PSOE fue el partido que mayor número de votos obtuvo: 251.106 votos (36,84 \%); UCD fue la segunda fuerza con 222.697 votos (32,67\%); y la tercera, el PCE, con 118.995 votos (17,46 \%). Alianza Popular (antiguo PP), que se presentó en coalición como Coalición 
Democrática $(C D)$, apenas consiguió 811 votos $(0,12 \%)$ dado que sólo presentó candidaturas en tres municipios del área metropolitana.

Tabla 2: Resultados electorales de los principales partidos en las elecciones municipales de 1979 en el área metropolitana de Valencia

\begin{tabular}{|l|r|r|}
\hline Partidos & \multicolumn{2}{|c|}{ Porcentaje de votos } \\
\hline PSPV-PSOE & 251.106 & $36.84 \%$ \\
\hline UCD & 222.697 & $32.67 \%$ \\
\hline PCE & 118.995 & $17.46 \%$ \\
\hline Otros & 98359 & $13.03 \%$ \\
\hline Tot769al & 691.157 & $100.00 \%$ \\
\hline
\end{tabular}

Fuente: Ministerio del Interior (Elaboración propia)

En 1983, la abstención fue del 28,03 \%, inferior a las anteriores elecciones. El PSPVPSOE consiguió 387.954 votos $(50,66 \%)$, mayoría absoluta en el área metropolitana. Debido a la desaparición electoral de UCD, la coalición AP-PDP-UL-UV obtiene relevantes resultados, con 235.264 votos $(30,72 \%)$, convirtiéndose en segunda fuerza. EI PCE sufre una notable caída: solo consigue 70.271 votos (9,17 \%). Otros partidos, como Centro Democrático y Social (CDS) y Unitat del Poble Valencià (UPV), se constituyen como fuerzas opositoras en algunas localidades.

Tabla 3: Resultados electorales de los principales partidos en las elecciones municipales de 1983 en el área metropolitana de Valencia

\begin{tabular}{|l|r|r|}
\hline Partidos & \multicolumn{2}{|c|}{ Púmercentaje de votos } \\
\hline PSPV-PSOE & 387.954 & $50.66 \%$ \\
\hline AP-PDP-UL-UV & 235.264 & $30.72 \%$ \\
\hline PCE & 70.271 & $9.17 \%$ \\
\hline Otros & 75.752 & $9.45 \%$ \\
\hline Total & 769.241 & $100.00 \%$ \\
\hline
\end{tabular}

Fuente: Ministerio del Interior (Elaboración propia)

Tabla 4: Resultados electorales de los principales partidos en las elecciones municipales de 1987 en el área metropolitana de Valencia

\begin{tabular}{|l|r|r|}
\hline PARTIDOS & Número de votos & Porcentaje de votos \\
\hline PSPV-PSOE & 317.256 & $39,64 \%$ \\
\hline UV & 121.612 & $15,20 \%$ \\
\hline CDS & 75.184 & $9,40 \%$ \\
\hline IU-UPV & 67.537 & $9,12 \%$ \\
\hline AP & 58.065 & $7,26 \%$ \\
\hline Otros & 160.608 & $19,38 \%$ \\
\hline Total & 800.262 & $100,00 \%$ \\
\hline
\end{tabular}

Fuente: Ministerio del Interior (Elaboración propia) 
En 1987, la participación creció hasta los 800.262 votos. El PSPV-PSOE obtuvo 317.2256 votos $(39,64 \%)$, perdiendo así la anterior mayoría absoluta. Le siguió Unió Valenciana (UV), con 121.612 votos (15,20\%). El CDS obtuvo 75.184 votos $(9,4 \%)$, seguido por IU-UPV con 67.537 votos (9,12 \%). En algunos municipios EUPV iba en coalición con UPV. En esta ocasión AP se presentó en solitario y tan solo obtuvo 58.065 votos (7,26 \%).

Las elecciones de 1991 son consideradas de continuidad, aunque se dan algunos cambios relevantes. La participación descendió hasta un 66,1\%. El PSPV-PSOE obtuvo 321.003 votos (41,7\%), mientras que el PP (antigua AP), obtuvo 172.179 (22,37\%), incremento significativo en buena parte a costa del CDS, que en estas elecciones solo consiguió 18.225 votos (2,37\%). UV incrementó ligeramente sus apoyos al obtener 131.956 votos $(17,14 \%)$. EUPV, que en estas elecciones se presentó en solitario, obtuvo 65.102 votos (8,56 \%); mientras que UPV, su anterior socio electoral en algunos municipios, obtuvo 12.071 votos $(1,57 \%)$, concentrados principalmente en la ciudad de Valencia. Habría que añadir que estas elecciones supusieron el inicio de un cambio sustancial del panorama político en el área al incrementarse el voto a las opciones de derecha, en especial al Partido Popular, en la ciudad de Valencia. En esta ciudad la suma de los votos a partidos de la derecha supera a la suma de la izquierda.

Tabla 5: Resultados electorales de los principales partidos en las elecciones municipales de 1991 en el área metropolitana de Valencia

\begin{tabular}{|l|r|r|}
\hline PARTIDOS & Número de votos & Porcentaje de votos \\
\hline PSPV-PSOE & 321.003 & $41,70 \%$ \\
\hline PP & 172.179 & $22,37 \%$ \\
\hline CDS & 18.225 & $2,37 \%$ \\
\hline UV & 131.956 & $17,14 \%$ \\
\hline EUPV & 65.102 & $8,56 \%$ \\
\hline UPV & 12.071 & $1,57 \%$ \\
\hline Otros & 49.124 & $6,29 \%$ \\
\hline Total & 769.660 & $100,00 \%$ \\
\hline
\end{tabular}

Fuente: Ministerio del Interior (Elaboración propia)

Las elecciones locales de 1995 fueron unas elecciones de ruptura. El total de votantes aumentó de manera considerable, hasta llegar a 932.151 votos (74,47 \%). Lo más llamativo es que el Partido Popular doblará sus votos respecto a los anteriores comicios: 376.586 votos (40,4 \%). Al tiempo, disminuyeron los apoyos al PSPV-PSOE: 282.992 votos $(30,35 \%)$. EUPV, por su lado, consiguió un notable incremento, si bien coaligado con Esquerra Valenciana (EV): 123.850 votos (13,29\%). UV también comenzó su declive, obteniendo tan solo 84.950 votos (9,11 \%). La UPV, coaligada con el Bloc Nacionalista, tampoco cosechó buenos resultados: 15.677 votos (1,68\%), resultados que supusieron su desaparición como alternativa electoral. 
Tabla 6: Resultados electorales de los principales partidos en las elecciones municipales de 1995 en el área metropolitana de Valencia

\begin{tabular}{|l|r|r|}
\hline PARTIDOS & Número de votos & Porcentaje de votos \\
\hline PP & 376.586 & $40,40 \%$ \\
\hline PSPV-PSOE & 282.992 & $30,35 \%$ \\
\hline EUPV-EV & 123.850 & $13,29 \%$ \\
\hline UV & 84.950 & $9,11 \%$ \\
\hline UPV & 15.677 & $1,68 \%$ \\
\hline Otros & 48.096 & $5,17 \%$ \\
\hline Total & 932.151 & $100,00 \%$ \\
\hline
\end{tabular}

Fuente: Ministerio del Interior (Elaboración propia)

Las elecciones de1999, al contrario que en otros ámbitos territoriales, no supusieron una modificación sustancial. La participación disminuye hasta los 867.340 votos (65 \%). El PP consigue de nuevo la mayoría, con 353.071 votos (40,7 \%), seguido por el PSPV-PSOE, con 288.679 votos (33,28 \%). Si estas elecciones se consideran de cambio, principalmente es debido a la gran pérdida de votos que obtuvo EUPV, formación que solo consiguió 53.555 votos $(6,17 \%)$ y también a la pérdida de apoyos de Unió Valenciana (UV), con 61.103 votos $(7,04 \%)$.

Tabla 7: Resultados electorales de los principales partidos en las elecciones municipales de 1999 en el área metropolitana de Valencia

\begin{tabular}{|l|r|r|}
\hline PARTIDOS & Número de votos & Porcentaje de votos \\
\hline PP & 353.071 & $40,70 \%$ \\
\hline PSPV-PSOE & 288.679 & $33,28 \%$ \\
\hline EUPV & 53.555 & $6,17 \%$ \\
\hline UV & 61.103 & $7,04 \%$ \\
\hline Otros & 110.932 & $12,81 \%$ \\
\hline Total & 867.340 & $100,00 \%$ \\
\hline
\end{tabular}

Fuente: Ministerio del Interior (Elaboración propia)

En 2003, la participación se recuperó ligeramente, rozando casi el 70\% con 948.616 votos. El Partido Popular mantiene su mayoría, con 404.160 votos (42,61 \%), seguida del PSPV-PSOE, con 330.872 votos (34,88\%). Los dos principales partidos han incrementado sus apoyos en unos 50.000 votos aproximadamente. EUPV, junto con Izquierda Republicana (IR), Esquerra Valenciana (EV) y Els Verds formaron la coalición llamada Entesa: 67.315 votos (7,1 \%). En estas elecciones asistimos a la caída definitiva de UV: 44.712 votos $(4,71 \%)$. Por último, apareció un nuevo partido que en elecciones posteriores irá ganando fuerza: el Bloc Nacionalista Valencià (Bloc). Logró entonces casi 37.000 votos $(4,35 \%)$. 
Tabla 8: Resultados electorales de los principales partidos en las elecciones municipales de 2003 en el área metropolitana de Valencia

\begin{tabular}{|l|r|r|}
\hline PARTIDOS & Número de votos & Porcentaje de votos \\
\hline PP & 404.160 & $42,61 \%$ \\
\hline PSPV-PSOE & 330.872 & $34,88 \%$ \\
\hline ENTESA & 67.315 & $7,10 \%$ \\
\hline UV & 44.712 & $4,71 \%$ \\
\hline BLOC & 36.994 & $4,35 \%$ \\
\hline Otros & 60.237 & $6,35 \%$ \\
\hline Total & 948.616 & $100,00 \%$ \\
\hline
\end{tabular}

Fuente: Ministerio del Interior (Elaboración propia)

En 2007 la participación fue similar a la de los anteriores comicios: 937.781 votos. El Partido Popular obtuvo 456.416 votos (48,67 \%). Le siguió el PSPV-PSOE, 324.083 votos $(34,56 \%)$. Sin embargo, EUPV, sufrió una importante caída, a pesar de haberse coaligado en algunos municipios con agrupaciones progresistas locales, Els Verds e IR: 44.178 votos $(4,71 \%)$. Por su parte, El Bloc, que en algunos sitios se coaligó con Els Verds, obtuvo 20.162 votos $(2,14 \%)$.

Tabla 9: Resultados electorales de los principales partidos en las elecciones municipales de 2007 en el área metropolitana de Valencia

\begin{tabular}{|l|r|r|}
\hline PARTIDOS & Número de votos & Porcentaje de votos \\
\hline PP & 456.146 & $48,67 \%$ \\
\hline PSPV-PSOE & 324.083 & $34,56 \%$ \\
\hline EUPV & 44.178 & $4,71 \%$ \\
\hline BLOC & 20.162 & $2,14 \%$ \\
\hline Otros & 93.212 & $9,92 \%$ \\
\hline Total & 937.781 & $100,00 \%$ \\
\hline
\end{tabular}

Fuente: Ministerio del Interior (Elaboración propia)

Tabla 10: Resultados electorales de los principales partidos en las elecciones municipales de 2011 en el área metropolitana de Valencia

\begin{tabular}{|l|r|r|}
\hline PARTIDOS & Número de partidos & Porcentaje de votos \\
\hline PP & 454.136 & $46,18 \%$ \\
\hline PSOE & 253.351 & $25,76 \%$ \\
\hline Compromís & 83.573 & $8,50 \%$ \\
\hline EUPV & 62.784 & $6,38 \%$ \\
\hline Otros & 100.008 & $13,18 \%$ \\
\hline Total & 953.852 & $100,00 \%$ \\
\hline
\end{tabular}

Fuente: Ministerio del Interior (Elaboración propia)

En 2011, los dos grandes partidos, a pesar de un descenso en votos y porcentaje, siguen teniendo la mayoría. EI PP consigue 454.136 votos (46,18\%). Le sigue el PSPV-PSOE 
con un descenso considerable: 253.351 votos (25,76 \%). Como tercera fuerza aparece Compromís, una coalición que incluye a partidos como El Bloc, Els Verds-Esquerra Ecologista del País Valenciá (EV-EE) o Iniciativa del Poble Valencià. Esta coalición consigue 83.573 votos (8,50 \%). EUPV, por su lado, incrementa sus votos de manera considerable: 62.784 votos $(6,38 \%)$.

Finalmente, en las elecciones de 2015 los dos grandes partidos han perdido buena parte de los apoyos que venían cosechando desde los años ochenta. El PP ha conseguido 253.498 votos $(25,56 \%)$, perdiendo casi la mitad de los que obtuvo en los comicios de 2011; y el PSPV-PSOE ha obtenido 212.067 votos (21,38\%), cuarenta mil votos menos que en los comicios de 2011. Por el contrario, otros partidos políticos han pasado a obtener unos apoyos ciertamente relevantes: Compromís, 193.017 votos (19,46\%); Ciudadanos, 106.143 votos $(10,70 \%)$ y fuerzas afines a Podemos -con todas las precauciones en relación a esta suma-, 80.361 votos $(8,10 \%)$. Por último, EU, si bien sufre un ligero descenso, en general se mantiene en los municipios del área: 56.029 votos (5,65\%).

Tabla 11: Resultados electorales de los principales partidos en las elecciones municipales de 2015 en el área metropolitana de Valencia.

\begin{tabular}{|l|r|r|}
\hline PARTIDOS & Número de votos & Porcentaje de votos \\
\hline PP & 253.498 & $25,56 \%$ \\
\hline PSOE & 212.067 & $21,38 \%$ \\
\hline Compromís & 193.017 & $19,46 \%$ \\
\hline Ciudadanos & 106.143 & $10,70 \%$ \\
\hline EUPV & 56.029 & $5,65 \%$ \\
\hline Podemos & 80.361 & $8,10 \%$ \\
\hline Otros & 90.353 & $9,11 \%$ \\
\hline Total & 991.468 & $100 \%$ \\
\hline
\end{tabular}

Fuente: Ministerio del Interior (Elaboración propia)

Gráfica 1: Evolución del voto por partidos en el área metropolitana (1979 - 2015)

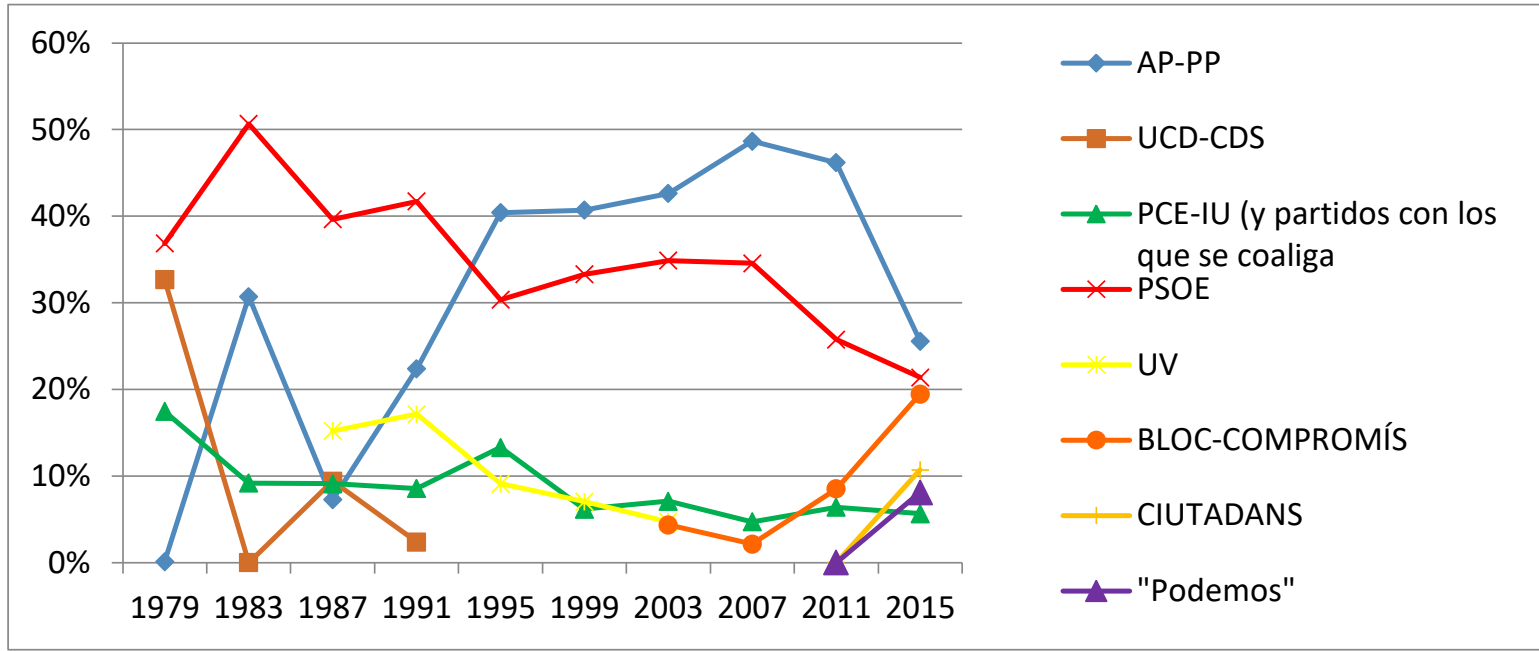

Fuente: Ministerio del Interior (Elaboración propia) 
En la gráfica 1 podemos observar la evolución de los principales partidos desde las primeras elecciones locales en el año 1979, tras la dictadura franquista hasta las últimas, del año 2015. Se observa con claridad el predominio del PSPV-PSOE en los años ochenta, el del PP en los noventa y la primera década del siglo XXI y la irrupción con fuerza en las últimas elecciones de Compromís, que prácticamente se iguala en votos a los dos principales paridos, y en menor medida de Ciudadanos y Podemos.

\section{EL RENDIMIENTO INSTITUCIONAL DE LOS VOTOS RECIBIDOS.}

El objetivo de unas elecciones es en último término la formación de gobiernos. Más allá de los resultados electorales en términos de representación conviene analizar el mayor o menor éxito de las fuerzas políticas en términos de consecución de parcelas de poder institucional. En la Figura 1 podemos observar de manera muy visual la evolución de las alcaldías al inicio de las diferentes legislaturas en el área metropolitana de Valencia.

Durante las primeras elecciones locales de 1979 predominan las alcaldías del PSPVPSOE y UCD, así como una mayor presencia del Partido Comunista de España en los gobiernos municipales. En las elecciones posteriores de 1983, 1987 y 1991, el PSPV-PSOE obtiene la mayoría de las alcaldías del área metropolitana, pero en este último año perdería la ciudad de Valencia a favor del PP. A partir de las elecciones de 1995 hay un punto de inflexión: el PP pasa a ser el partido más votado y a tener una influencia creciente. No obstante, hasta las elecciones de 2007 el número de alcaldías del Partido Popular sigue siendo similar a las del PSPV-PSOE. En 2011, el PP se hace con la mayoría de las alcaldías. Finalmente, en 2015 las fuerzas políticas de izquierda obtienen de nuevo amplias mayorías para formar gobiernos, aun en coalición.

En estos mapas también podemos observar de forma clara el comportamiento institucional del cinturón rojo de Valencia. Se hace visible en mayor medida en las elecciones de 1995, 1999 y 2003; se va volatilizando en las elecciones de 2007 y 2011; y en 2015 reaparece con fuerza, si bien conformando distintas tonalidades de rojo.

Las elecciones de 2015 han supuesto una clara ruptura de la tendencia marcada desde 1991. En el mapa de la Figira 2 se puede observar cómo ha quedado el reparto de las alcaldías. Se constata una mayor extensión de los municipios gobernados por fuerzas políticas de izquierdas, con el PSPV-PSOE a la cabeza, seguido de Compromís, mientras que el Partido Popular no tendría un número de alcaldías significativo. También se observa desde el punto de vista del reparto geográfico como en los municipios más cercanos a Valencia la presencia de Compromís es mucho mayor que en los que se encuentran más alejados, que se encuentran más al interior, donde predomina el PSPV-PSOE. 
Figura 1: Evolución de las alcaldías en el área metropolitana al inicio de cada legislatura (1979-2011)

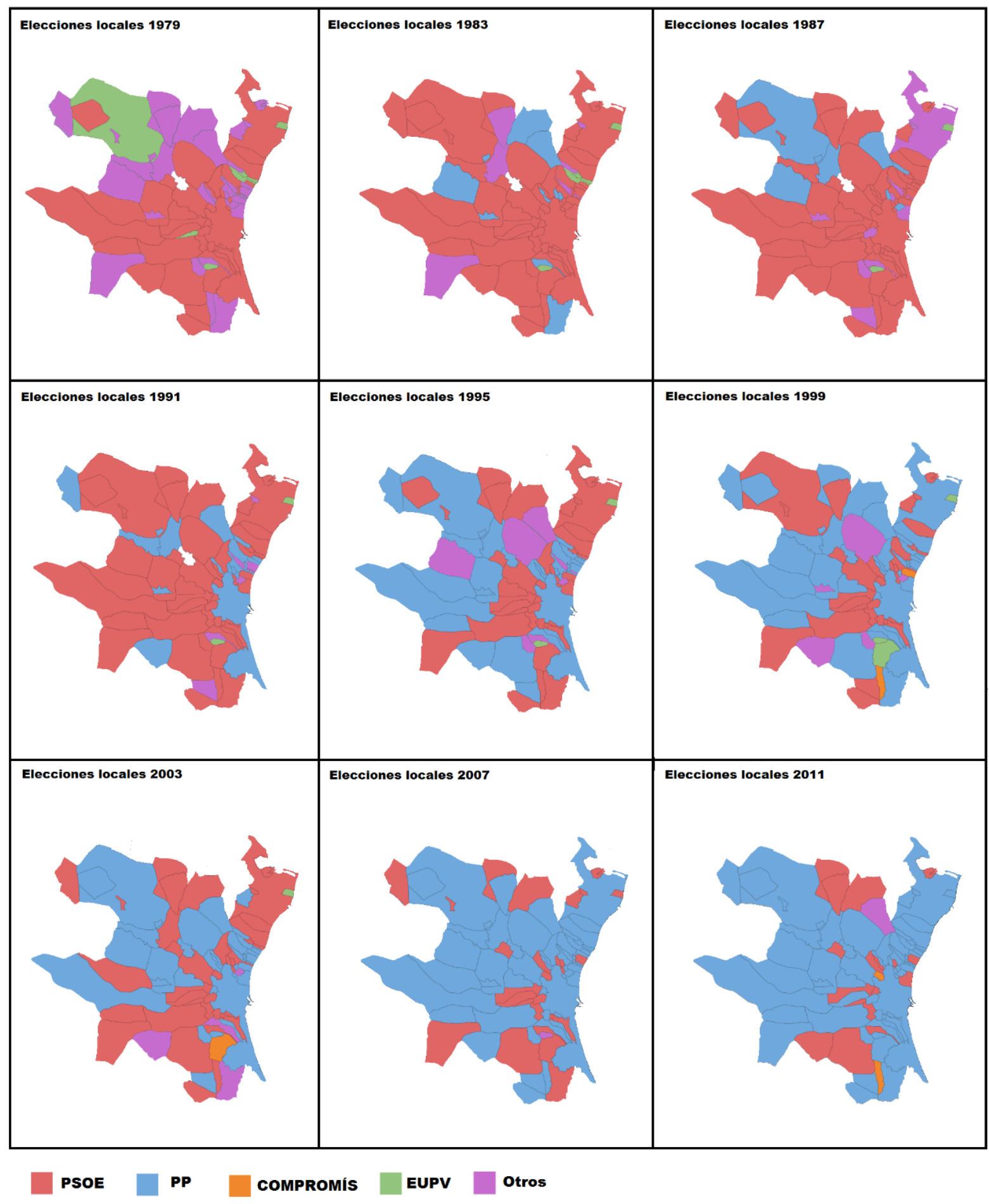

Fuente: ARGOS (Elaboración propia) 
Figura 2: Mapa área metropolitana de Valencia según partido en la alcaldía al inicio de la legislatura (2015)

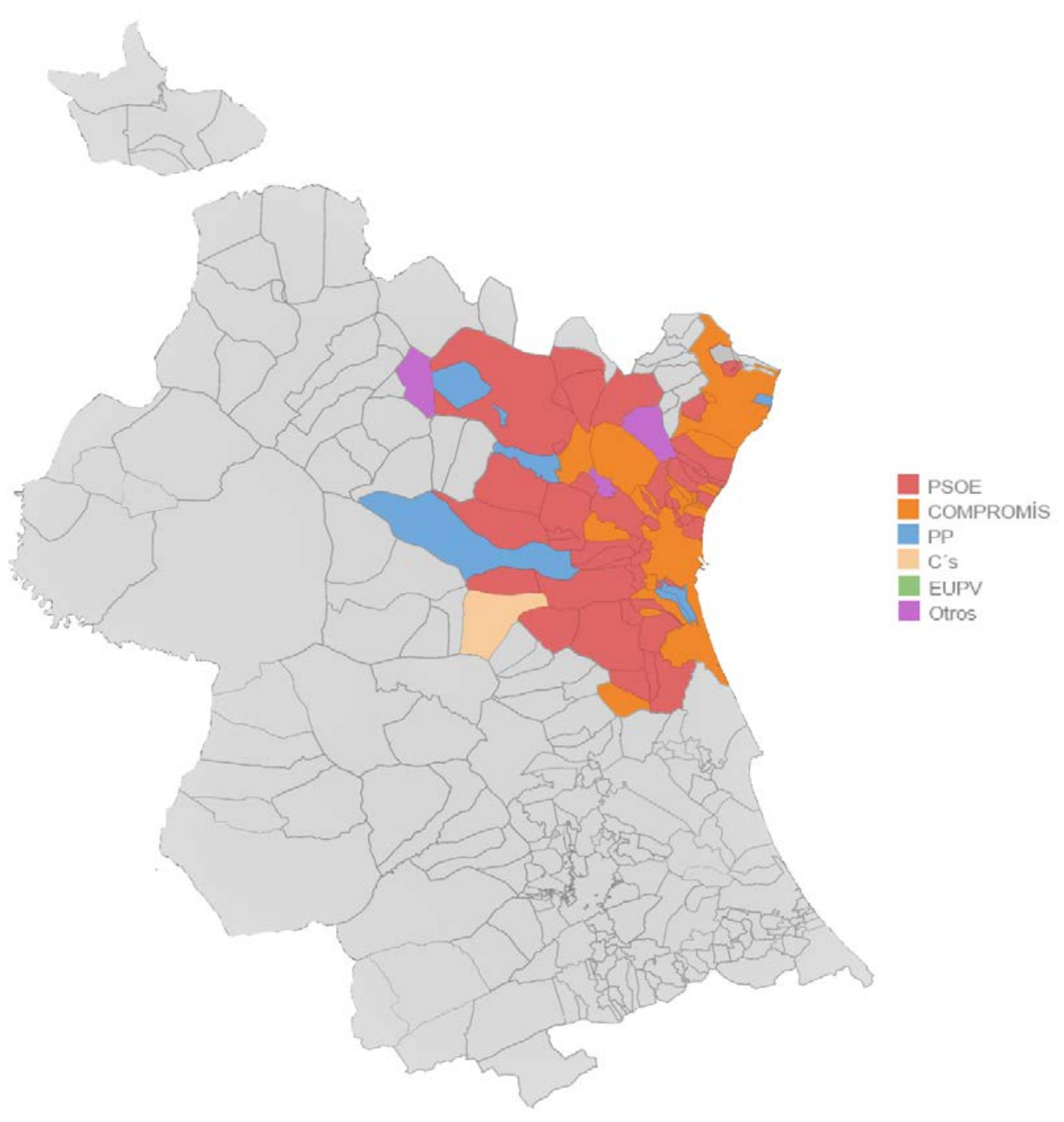

Fuente: Argos www.argos.gva.es (Elaboración propia)

Los números son claros: PSPV-PSOE, 48 alcaldías (63,2\%): Compromís, 17 alcaldías (22,4\%); PP, 8 alcaldías (10,5\%); Podemos (Villar Puede), 1 alcaldía (1,3\%); Independientes, 2 alcaldías (2,6\%). En términos de poder institucional, la izquierda es la gran vencedora en los municipios del área metropolitana: los municipios gobernados por PSPV-PSOE y Compromís representan más del $85 \%$. Estos partidos son los grandes triunfadores en estas elecciones: principalmente el PSPV-PSOE que rentabiliza más que nadie su porcentaje de votos; y también Compromís que, como fuerza emergente, se hace con un porcentaje relevante de alcaldías, entre ellas la emblemática de la ciudad de Valencia. La derecha sólo ha conseguido promover a sus candidatos en poco más del $10 \%$ de los municipios y todo ellos de pequeña entidad poblacional. 
Conviene hacer notar la importancia que tiene la fragmentación del voto en relación al tipo de gobierno que se ha conformado en los ayuntamientos. Así, por ejemplo, de las alcaldías del PSPV-PSOE, 31 son en coalición o con apoyos de otras fuerzas en el pleno y sólo 17 en solitario; de las alcaldías de Compromís, 15 lo son en coalición o con apoyos y sólo 2 en solitario; la alcaldía de Podemos es en coalición; se reparten las de los independientes; y sólo en el caso del PP predominan las alcaldías en solitario, 6 frente a 2 en coalición o con apoyos. Estos números son significativos: de las 76 alcaldías, 50 se conforman por acuerdos expresos de diferentes fuerzas políticas, esto es, el 65,8\% de las alcaldías responden a un gobierno de coalición o con apoyos expresos de otras fuerzas políticas del pleno.

Si comparamos los resultados entre las alcaldías a principio de legislatura entre 2011 y 2015 el cambio de color político del área metropolitana en términos de poder institucional resulta evidente. En términos cuantitativos el número de alcaldías que tiene cada partido en el inicio de las legislaturas de los años 2011 y 2015 sería el siguiente:

- Alcaldías al inicio de la legislatura del año 2011: Partido Popular, 55; PSPV-PSOE, 18; Compromís, 2; UPDN (Unión Popular de Náquera), 1.

- Alcaldías al inicio de la legislatura del año 2015: PSPV-PSOE, 48; Compromís, 17; Partido Popular, 8; Podemos, 1; UPN (Unión Popular de Náquera), 1; AISAB (Agrupación Independiente de San Antonio de Benagéber), 1.

Habría que precisar que el reparto de alcaldías que hemos reflejado es el que se produce al inicio de la legislatura con dos excepciones: el PP de hecho empezó con 9 alcaldías, si bien de forma casi inmediata perdió Chiva donde dimitió el alcalde, pasando a gobernar Compromís; algo parecido ocurrió en Turís donde la legislatura empezó con un alcalde de Ciudadanos, pero al mes pasó a manos del PSPV-PSOE. Además, en seis municipios las fuerzas que se han coaligado se han repartido la tenencia de la alcaldía dividiendo el tiempo de la legislatura de manera más o menos proporcional al número de concejales obtenidos por cada una de ellas. Sea como sea, el vuelco es espectacular:

- EL PP ha pasado de ostentar 55 alcaldías $(72,4 \%)$ en el área metropolitana de Valencia a sólo 8 (10,5\%), esto es, 47 alcaldías menos;

- EI PSPV-PSOE ha pasado de ostentar 18 alcaldías $(23,7 \%)$ a ostentar 48 alcaldías (63,2\%), esto es, 30 alcaldías más;

- Compromís, de ostentar 2 alcaldías (2,6\%) a ostentar 17 (22,4\%), esto es, 15 alcaldías más.

En los mapas de la figura 3 se observa claramente como de un predominio abrumador en la tenencia de alcaldías por parte del PP en 2011 hemos pasado a un predominio abrumador por parte de la izquierda y muy especialmente del PSPV-PSOE y de Compromís. 
Figura 3: Comparación partido gobernante al inicio de la legislatura en las elecciones locales de 2011 y 2015 en el área metropolitana de Valencia

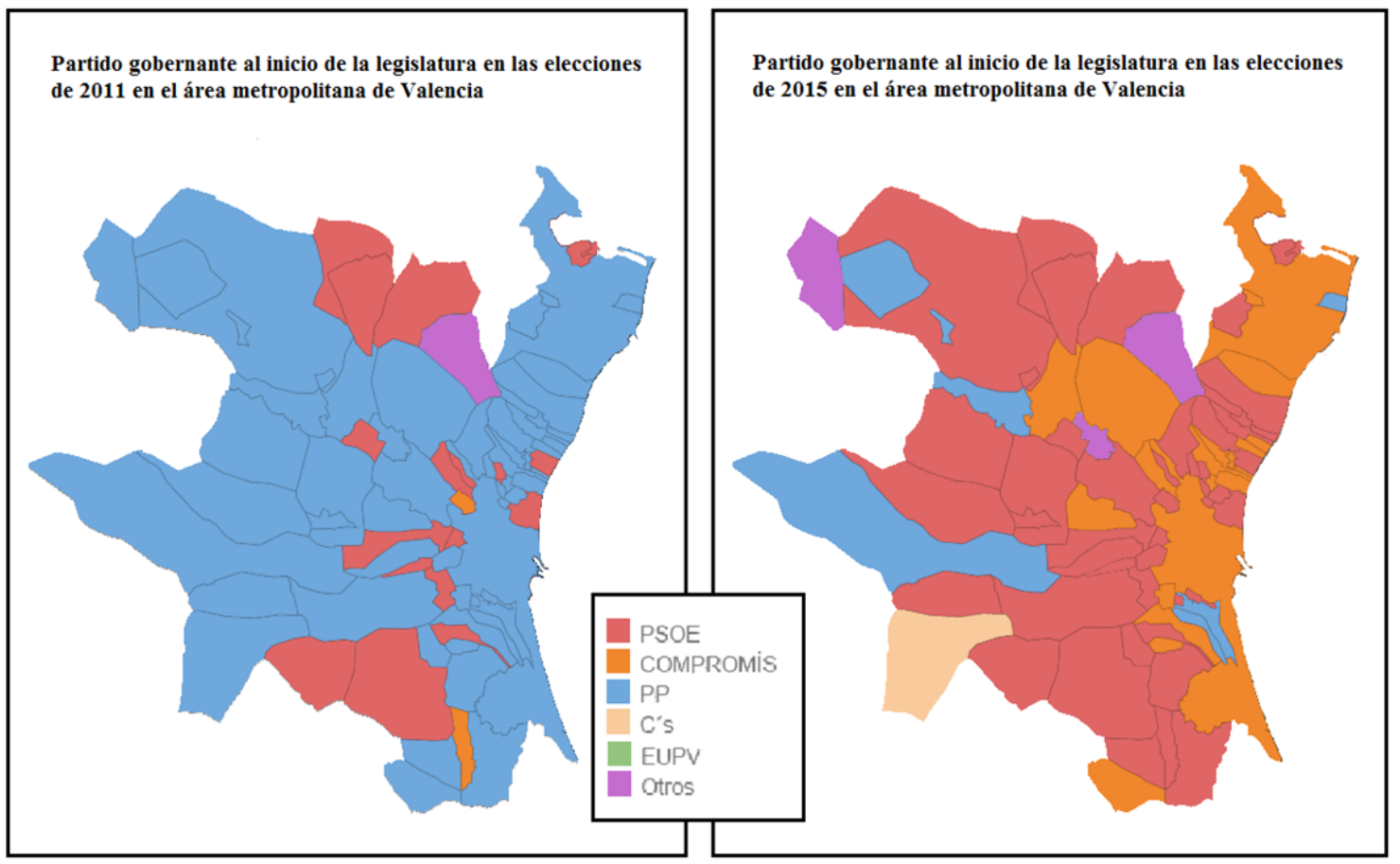

Fuente: ARGOS (Elaboración propia)

En definitiva, después de las elecciones de 2015 se puede afirmar no sólo que -en términos de comportamiento electoral- el sistema de partidos ha evolucionado hacia uno más plural, donde el voto se reparte entre más partidos relevantes; sino que, además -en términos de poder institucional- se han producido las siguientes novedades: en primer lugar, los municipios del área metropolitana están gobernados en su gran mayoría por partidos políticos situados a la izquierda del espectro político; en segundo lugar, en la mayoría de casos se ha tenido que recurrir a pactos para la formación de esos gobiernos de izquierdas; $y$, en tercer lugar y como consecuencia, se ha producido una mayor heterogeneidad en los gobiernos del área metropolitana de Valencia..

\section{VOTO SEGÚN TAMAÑO DEL MUNICIPIO.}

El análisis electoral desde una perspectiva geográfica o territorial hace especial incidencia en el tamaño del municipio como factor explicativo en un comportamiento electoral diferenciado entre los electores. En este epígrafe tratamos de aproximarnos a la incidencia de este factor en el área metropolitana de Valencia.

En la gráfica 2 observamos el peso relativo que tiene cada municipio o grupo de municipios según su población respecto al total del área metropolitana. Valencia, junto con Torrent, Paterna y Sagunt, ocupan más de la mitad de la población del área metropolitana. Valencia, especialmente, pues este municipio representa el $42,43 \%$ del total de la población del área. Esto condiciona que los resultados electorales en estas 
cuatro poblaciones y especialmente en Valencia ciudad sean decisivos para el área en su conjunto. Cabe señalar también que en el área, fuera de estos grandes municipios, hay un buen número de tamaño mediano -entre 10.000 y 50.000 habitantes-que juntos suman otro importante porcentaje de la población: 35,25\%. Por el contrario, los municipios pequeños -menos de 10.000 habitantes- apenas reúnen al 10,86 \% de la población del área.

Gráfica 2: Peso poblacional por grupos de municipios del área metropolitana

\section{Peso poblacional por grupos de municipios del área metropolitana}

(INE 2015)

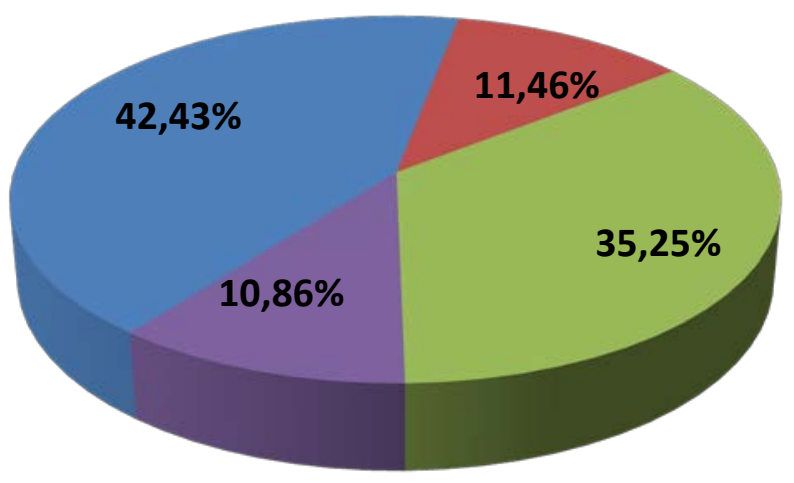

- Valencia

más de 50.000

entre 10.000 y 50.000

menos de 10.000

Fuente: Ministerio del Interior (Elaboración propia)

A partir de estas características determinantes en la configuración geográfica del área metropolitana, mostramos a continuación los resultados de los principales partidos de las elecciones del 2015 en los municipios agrupados según el peso poblacional.

La tabla 12 ofrece una información relevante de la diferente distribución de los apoyos según el tamaño poblacional de los municipios para cada uno de los partidos:

- El PP $-25,56 \%$ de los votos en el conjunto del área- incrementa sus apoyos especialmente en los municipios pequeños $(29,65 \%)$ perdiendo algo respecto a su media en los municipios medianos.

- El PSPV-PSOE -21,38\% de los votos en el área- incrementa sus apoyos especialmente en los municipios medianos $(28,06 \%)$ y en los municipios pequeños $(28,15 \%)$, se mantiene en los grandes $(20,92 \%)$ y se desfonda en la ciudad de Valencia donde se queda en un mero $14,07 \%$ de los votos.

- Compromís -19,46\% de los votos en el área- representa el fenómeno inverso al del PSPV-PSOE: incrementa sus apoyos especialmente en la ciudad de Valencia 
$(23,28 \%)$; sin embargo, sus porcentajes disminuyen especialmente en los municipios medianos $(16,41 \%)$ y en los pequeños $(16,57 \%)$.

- Ciudadanos -10,70\% de los votos en el área- experimenta un fenómeno parecido al de Compromís: incrementa sus apoyos especialmente en la ciudad de Valencia $(15,38 \%)$; sin embargo, sus porcentajes disminuyen en los municipios medianos $(7,69 \%)$ y en los pequeños (4,97\%).

- Podemos $-8,10 \%$ de los votos en el área con todas las salvedades comentadasrepite el esquema anterior: incrementa sus apoyos especialmente en la ciudad de Valencia $(9,81 \%)$; sin embargo, sus porcentajes disminuyen en los municipios medianos (6,92\%) y en los pequeños $(5,58 \%)$.

- Finalmente, EUPV $-5,65 \%$ de los votos en el área- se aparta de los perfiles anteriores. Sus apoyos se siguen concentrando en el antiguo cinturón rojo: obtiene un más que meritorio $8,58 \%$ de los votos en las ciudades grandes y un $6,45 \%$, en los municipios medianos. Es en la ciudad de Valencia $(4,71 \%)$ y en los municipios pequeños $(4,04 \%)$ donde sus porcentajes se reducen a la mitad.

Tabla 12: Resultados de los principales partidos por grupos de municipios según peso poblaciones en las elecciones locales de 2015 (número de votos y porcentajes)

\begin{tabular}{|c|c|c|c|c|c|c|c|c|c|}
\hline & PP & PSOE & Compromís & Ciudadanos & EUPV & Podemos & Otros & \%Participación & \\
\hline Valencia & V & 105.963 & 57.981 & 95.958 & 63.399 & 19.424 & 40.420 & 32.576 & $72,11 \%$ \\
\hline & $\%$ & $25,71 \%$ & $14,07 \%$ & $23,28 \%$ & $15,38 \%$ & $4,71 \%$ & $9,81 \%$ & $7,91 \%$ & \\
\hline $\begin{array}{r}\text { Municipios de } \\
\text { más de } \mathbf{5 0 . 0 0 0} \\
\text { habitantes } \\
\text { (Paterna, } \\
\text { Torrent, } \\
\text { Sagunt) }\end{array}$ & V & 24.961 & 22.210 & 19.771 & 9.784 & 9.109 & 8.996 & 11.324 & $67,62 \%$ \\
\hline & $\%$ & $23,51 \%$ & $20,92 \%$ & $18,62 \%$ & $9,21 \%$ & $8,58 \%$ & $8,47 \%$ & $10,66 \%$ & \\
\hline $\begin{array}{r}\text { Municipios } \\
\text { entre } 10.000 \text { y } \\
50.000 \\
\text { habitantes (31 } \\
\text { municipios) } \\
\end{array}$ & V & 88.066 & 99.116 & 57.998 & 27.176 & 22.784 & 24.449 & 33.629 & $71,56 \%$ \\
\hline & $\%$ & $24,93 \%$ & $28,06 \%$ & $16,41 \%$ & $7,69 \%$ & $6,45 \%$ & $6,92 \%$ & 9,52 & \\
\hline $\begin{array}{r}\text { Municipios de } \\
\text { menos de } \\
10.000 \\
\text { habitantes (41 } \\
\text { municipios) }\end{array}$ & V & 34.508 & 32.760 & 19.290 & 5.784 & 4.712 & 6.496 & 12.824 & $75,36 \%$ \\
\hline & $\%$ & $29,65 \%$ & $28,15 \%$ & $16,57 \%$ & $4,97 \%$ & $4,04 \%$ & $5,58 \%$ & $11,01 \%$ & \\
\hline
\end{tabular}

Fuente: Ministerio del Interior (Elaboración propia)

En términos globales, podemos afirmar que es la ciudad de Valencia la que ha marcado la diferencia respecto al resto de los municipios del área. Su tamaño (o sus dinámicas) no afecta al porcentaje de apoyos que recibe el PP, que se sitúa en su media del área, pero sí afecta especialmente al PSPV-PSOE en sentido negativo (pierde un tercio de sus apoyos en términos porcentuales) mientras que es en la ciudad de Valencia donde las fuerzas emergentes -Compromís, Ciudadanos y Podemos- han recibido un especial plus en el apoyo ciudadano frente a otros tramos poblacionales. 
En la gráfica 3 se puede apreciar visualmente el diferente comportamiento electoral de los ciudadanos respecto a los partidos políticos según los tramos de población:

- El PP tiene apoyos estables que se incrementan en los municipios pequeños.

- EUPV también tiene apoyos más o menos estables que se incrementan en los municipios medianos.

- EI PSPV-PSOE incrementa sus apoyos progresivamente conforme disminuye el tamaño poblacional de los municipios.

- Compromís, Ciudadanos y Podemos incrementan sus apoyos progresivamente conforme se incrementa el tamaño poblacional de los municipios.

Gráfica 3: Resultados de los principales partidos por grupos de municipios según peso poblaciones en las elecciones locales de 2015 (número de votos y porcentajes).

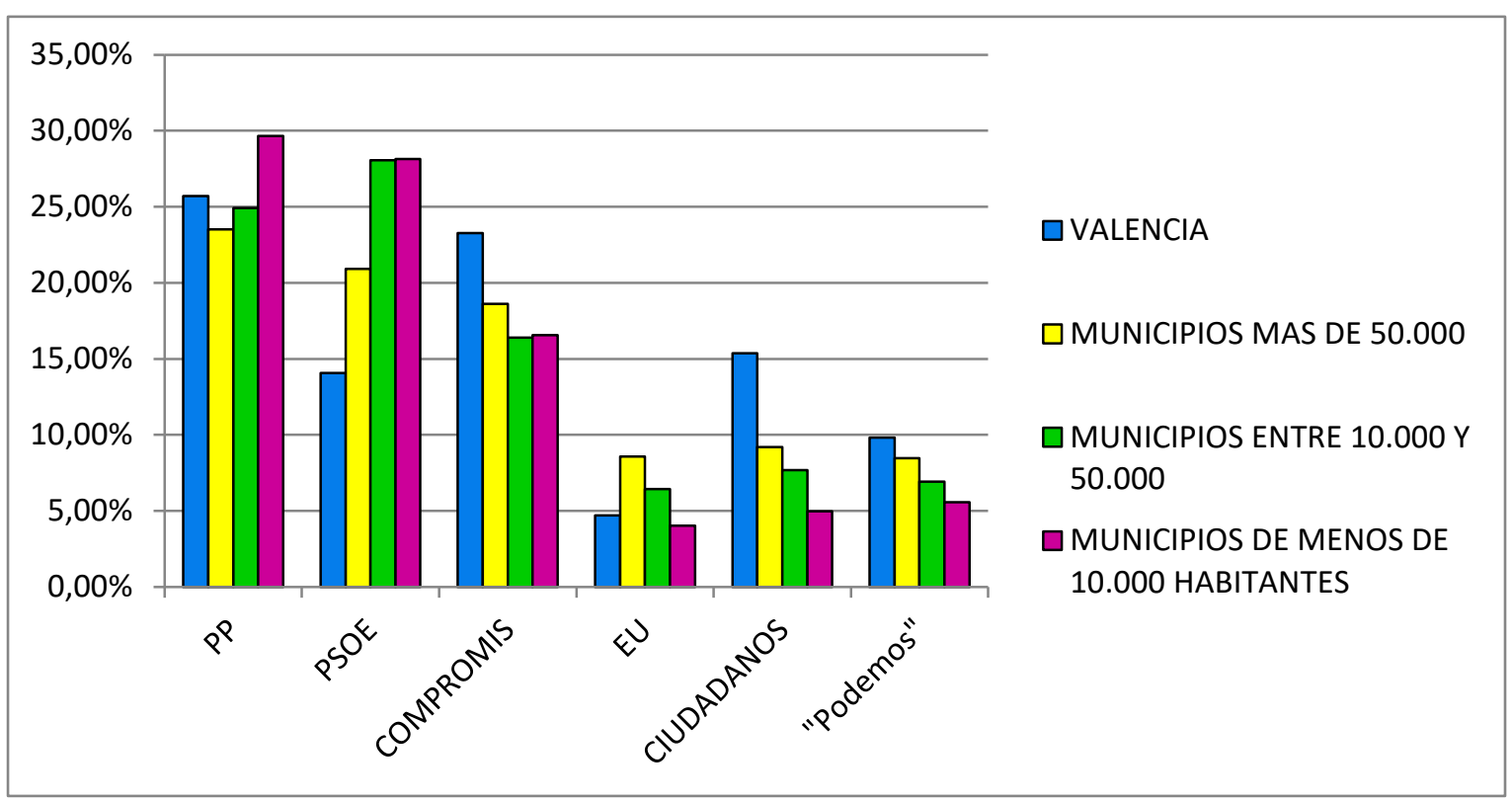

Fuente: Ministerio del Interior (Elaboración propia)

Más allá de las razones explicativas de ese diferente comportamiento, es conveniente realizar una breve descripción de la distribución de los apoyos entre las fuerzas políticas según cada tramo de población.

\section{Valencia:}

EI PP marca la caída más significativa de su historia en su principal bastión electoral, quedándose en un $25,71 \%$ de los votos. La segunda fuerza política en la ciudad de Valencia ha pasado a ser Compromís, con un $23,28 \%$ de los votos, superando claramente a la otrora segunda fuerza que era el PSOE, partido que cae al cuarto puesto con el $14,07 \%$ de los votos. Como tercera fuerza se sitúa Ciudadanos, con el 15,38\% de los votos. Valencia en Comú, agrupación de Podemos para las elecciones locales en la ciudad 
de Valencia, ha conseguido un 9,81 \% de los votos. Es dónde más apoyo recibe del área metropolitana. EUPV, con un $4,71 \%$ de los votos, no ha conseguido representación.

\section{Otros municipios de más de 50.000 habitantes:}

Este grupo está compuesto por tres municipios: Torrent, Paterna y Sagunt. EI PP, a pesar de ser la primera fuerza en votos, apenas tiene presencia en ellos (23,51\%). El PSPVPSOE mantiene a duras penas un porcentaje cercano a la media del área, con un $20,92 \%$ de los votos. Compromís también decae ligeramente respecto a su media, con un 18,62\% de los votos. Lo mismo ocurre con Ciudadanos, con un 9,21 \% de los votos. Podemos, sin embargo, también en este tramo se sitúa por encima de su media, aunque hay que decir que muy ligeramente (8,47\%). EUPV, por el contrario, supera ampliamente su media $(8,58$ $\%)$, superando incluso a Podemos.

\section{Municipios entre 10.000 y 50.000 habitantes:}

El partido más votado, singularmente, es el PSPV-PSOE con el 28,06\% de los votos y no el Partido Popular que se queda con un 24,93\%. En cambio, Compromís, aquí es donde posee menos fuerza (16,41\%). Ciudadanos, por su parte, consigue un 7,69 \%. Las confluencias de Podemos obtienen un 6,92 \% de los votos, superando por muy poco el apoyo que EU $(6,45 \%)$.

\section{Municipios de menos de 10.000 habitantes:}

El Partido Popular y el PSOE obtienen sus mejores resultados: respectivamente, un $29,65 \%$ y un $28,15 \%$ de los votos. Conviene señalar, no obstante, que, a pesar de que siguen siendo los principales partidos en este tramo poblacional, también aquí han perdido una buena parte de sus apoyos. Compromís, a pesar de perder porcentaje de apoyos en este tramo (16,57\%), es la tercera fuerza política. Podemos $(5,58 \%)$, Ciudadanos $(4,97 \%)$ y EUPV $(4,04 \%)$ gozan claramente de un menor apoyo electoral y con estos porcentajes no obtienen representación en las corporaciones municipales salvo en casos excepcionales.

Como conclusión, podemos señalar que en las poblaciones con mayor número de habitantes existe unas corporaciones municipales más plurales; que en ellas los partidos tradicionales (PP y PSOE) tienen menos fuerza relativa en comparación con la que disfrutan en otros tramos poblacionales, especialmente el PSPV para el caso de la ciudad de Valencia; que los partidos emergentes como Compromís, Ciudadanos y las confluencias de Podemos poseen gran relevancia institucional, lo que les ha permitido en algunos casos llegar a ocupar o, cuanto menos, participar en la conformación de alcaldías, como en Valencia ciudad. En cambio, en las localidades con menor número de población, especialmente en los municipios pequeños, las fuerzas tradicionales, a pesar de haber perdido apoyos, siguen siendo las mayoritarias y han podido conformar con más facilidad gobiernos en solitario. 


\section{Abstención:}

Si atendemos al comportamiento electoral del área metropolitana en términos de participación nos encontramos con la sorpresa de un comportamiento errático en relación a la progresión en tramos de población.

Tabla 13: Abstención en el A.M. de Valencia en las elecciones locales del 2015

\begin{tabular}{l|c|}
\hline Valencia & Abstención \\
\hline Municipios de más de 50.000 habitantes & $27,89 \%$ \\
\hline $\begin{array}{l}\text { Municipios entre } 10.000 \text { y } 50.000 \\
\text { habitantes }\end{array}$ & $32,37 \%$ \\
\hline $\begin{array}{l}\text { Municipios de menos de } 10.000 \\
\text { habitantes }\end{array}$ & $28,43 \%$ \\
\hline
\end{tabular}

Fuente: Ministerio del Interior (Elaboración propia)

La abstención en el área metropolitana de Valencia ha sido de un 28,22\%. En Valencia ciudad, la abstención apenas se ha situado unas décimas por debajo de la media. En el caso de los municipios de entre 10.000 y 50.000 habitantes, por el contrario, se ha situado más de tres puntos por encima de la media (32,37\%). Más relevante, si cabe, es el caso de las localidades de menos de 10.000 habitantes, dónde la abstención baja significativamente en relación a la media $(24,63 \%)$, en concreto más de tres puntos por debajo de la media. Es en las localidades de más de 50.000 habitantes, dónde la abstención es más elevada, con más de un $32 \%$, aproximadamente unos 4 puntos por encima de la media. Lo más significativo de la tabla es que la abstención va de menos a más conforme los municipios crecen en población hasta llegar a la ciudad de Valencia donde disminuye de forma considerable.

\section{VOTO POR COMARCAS DE L'HORTA.}

Las comarcas forman tradicionalmente parte de la forma de relacionarse y convivir los valencianos. Los flujos e interrelaciones en su seno afectan a la economía, a la circulación de personas, a la cultura, etc., pero también pueden tener una afectación en términos electorales. Nuestro propósito en este epígrafe es analizar la incidencia de la comarca como factor explicativo en un comportamiento electoral diferenciado entre los electores en el área metropolitana de Valencia.

En la tabla 14 podemos observar los resultados de las elecciones locales del año 2015 en las comarcas de l'Horta según la clasificación tradicional. 
Tabla 14: Resultados de las elecciones locales de 2015 en I'Horta y la ciudad de Valencia (número de votos y porcentajes)

\begin{tabular}{|c|c|c|c|c|c|c|c|c|c|}
\hline - & & PP & PSOE & Compromis & Ciudadanos & EUPV & "Podemos" & Otros & $\begin{array}{r}\% \\
\text { participación }\end{array}$ \\
\hline \multirow[t]{2}{*}{ Valencia } & № & 105.963 & 57.981 & 95.958 & 63.399 & 19.424 & 40.420 & 32.576 & $72,11 \%$ \\
\hline & $\%$ & $25,71 \%$ & $14,07 \%$ & $23,28 \%$ & $15,38 \%$ & $4,71 \%$ & $9,81 \%$ & $7,91 \%$ & \\
\hline \multirow[t]{2}{*}{$\begin{array}{l}\text { Horta } \\
\text { Nord } \\
\end{array}$} & № & 31.914 & 31.472 & 24.237 & 9.249 & 5.654 & 9.244 & 13.046 & $73,33 \%$ \\
\hline & $\%$ & $25,56 \%$ & $25,21 \%$ & $19,41 \%$ & $7,41 \%$ & $4,52 \%$ & $7,40 \%$ & $10,45 \%$ & \\
\hline \multirow[t]{2}{*}{$\begin{array}{r}\text { Horta } \\
\text { Oest } \\
\end{array}$} & № & 43.121 & 59.220 & 27.762 & 14.489 & 9.754 & 15.538 & 12.913 & $70,07 \%$ \\
\hline & $\%$ & $23,58 \%$ & $32,39 \%$ & $15,18 \%$ & $7,92 \%$ & $5,33 \%$ & $8,50 \%$ & $7,06 \%$ & \\
\hline \multirow[t]{2}{*}{$\begin{array}{r}\text { Horta } \\
\text { Sud } \\
\end{array}$} & № & 25.912 & 25.185 & 13.914 & 7.499 & 7.971 & 4.997 & 8.684 & $71,65 \%$ \\
\hline & $\%$ & $27,51 \%$ & $26,74 \%$ & $14,77 \%$ & $7,9 \%$ & $8,46 \%$ & $5,30 \%$ & $9,22 \%$ & \\
\hline
\end{tabular}

Fuente: Ministerio del Interior (Elaboración propia)

La tabla ofrece una información relevante de la diferente distribución de los apoyos según comarcas para cada uno de los partidos. Así, por ejemplo:

- $\quad$ EI PP $-25,56 \%$ de los votos en el conjunto del área- incrementa sus apoyos especialmente en l'Horta Sud $(27,51)$ y, sin embargo, los reduce en l'Horta Oest $(23,58 \%)$.

- $\quad$ EI PSPV-PSOE -21,38\% de los votos en el área- incrementa sus apoyos en las tres comarcas alrededor de Valencia, especialmente en l'Horta Oest (32,39\%) y también en l'Horta Sud $(26,74 \%)$ y l'Horta Nord $(25,21 \%)$ y, sin embargo, no recibe apenas apoyo de los ciudadanos en la ciudad de Valencia (14,07\%).

Compromís $-19,46 \%$ de los votos en el área- incrementa sus apoyos especialmente en la ciudad de Valencia $(23,28 \%)$ que, en sentido contrario, se ven reducido especialmente en l'Horta Sud (14,77\%) y en l'Horta Oest $(15,18 \%)$.

Ciudadanos $-10,70 \%$ de los votos en el área- incrementa sus apoyos especialmente en la ciudad de Valencia (15,38\%) mientras que los ve reducidos en el resto de las comarcas: I'Horta Nord (7,41\%), I'Horta Sud (7,90\%) y l'Horta Oest (7,91\%).

EU $-5,65 \%$ de los votos en el área- incrementa sus apoyos especialmente en l'Horta Sud $(8,46 \%)$ mientras que los ve reducidos especialmente en l'Horta Nord $(4,52 \%)$ y en la ciudad de Valencia $(4,71 \%)$.

Podemos $-8,10 \%$ de los votos en el área- incrementa sus apoyos especialmente en la ciudad de Valencia $(9,81 \%)$ y los reduce considerablemente en l'Horta Sud (5,30\%).

Los resultados reflejan bastante bien el anclaje de los partidos políticos algunos fenómenos relacionados con el perfil de los votantes de cada una de las formaciones. Así, por ejemplo, la fortaleza que mantiene EU en l'Horta Sud, comarca que donde en el pasado el comunismo ha tenido un cierto predicamento debido a su floreciente industria. Precisamente la fortaleza de EU en esta comarca se corresponde con las dificultades de Podemos para conseguir votos en la misma. También característica es la fortaleza de las fuerzas emergentes en la ciudad de Valencia que se corresponde con la crisis en la misma, por un lado, del PP y, especialmente, del PSPV-PSOE. Es un buen reflejo de que el cambio de comportamiento electoral se ha producido especialmente en las grandes áreas urbanas. 
En la siguiente gráfica se muestran los resultados según partidos en las distintas comarcas de l'Horta y de la ciudad de Valencia.

Gráfica 4: Resultados de las elecciones locales del 2015 por zonas geográficas en el área metropolitana de Valencia.

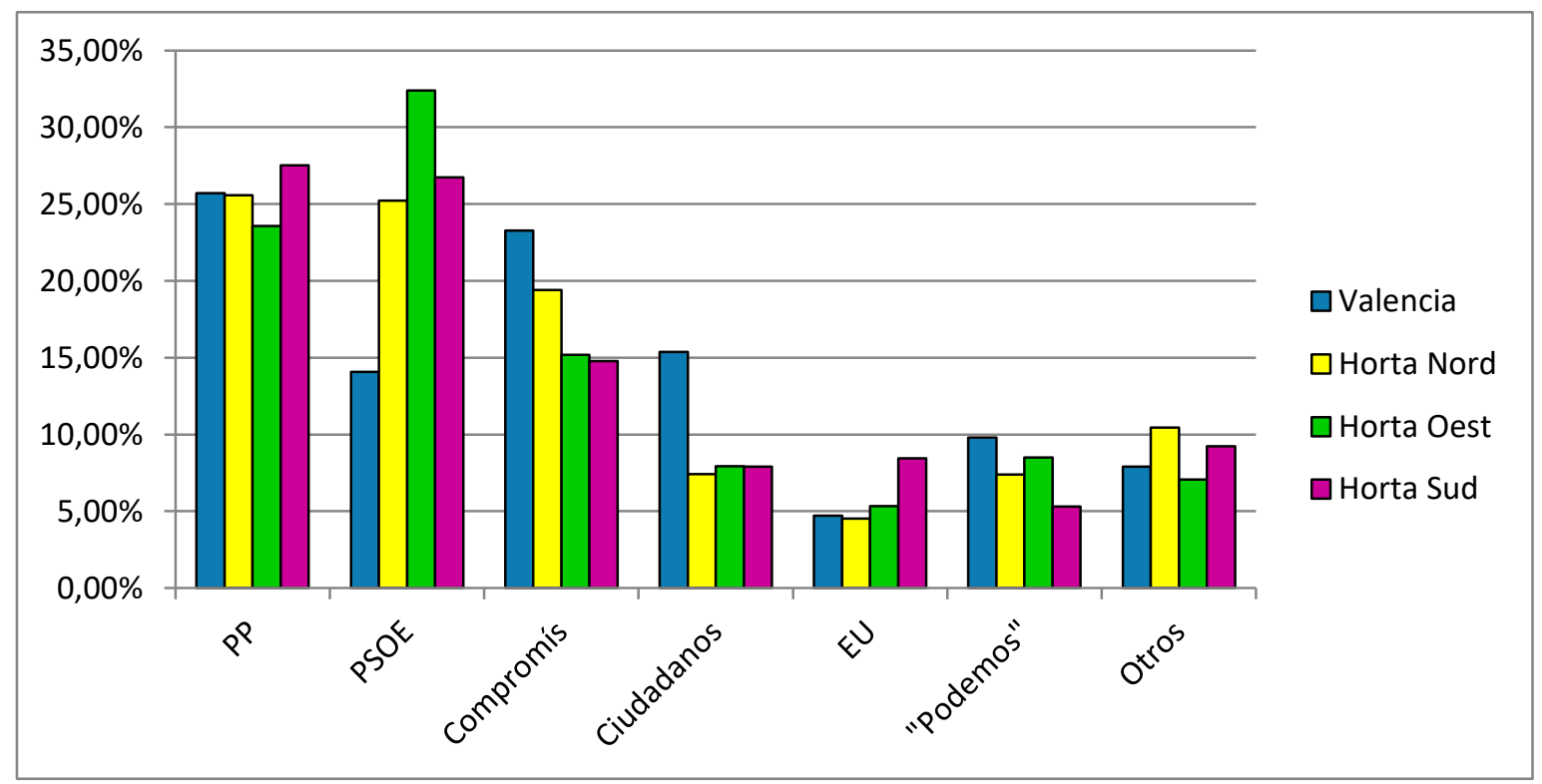

Fuente: Ministerio del Interior (Elaboración propia)

La gráfica permite una fácil visualización del comportamiento diferenciado de los electores respecto a los partidos políticos en función de las comarcas de referencia:

- El PP disfruta de apoyos homogéneos en todas las comarcas con la excepción de I'Horta Oest donde obtiene sus peores resultados.

- EL PSPV-PSOE sufre un fuerte descalabro en la ciudad de Valencia y, sin embargo, obtiene un resultado relevante en l'Horta Oest.

- Compromís tiene sus mejores resultados en la ciudad de Valencia y en l'Horta Nord, siendo discretos en las otras dos comarcas de l'Horta.

- Ciudadanos concentra sus apoyos fundamentalmente en la ciudad de Valencia

- EU, por su parte, lo hace en l'Horta Sud.

- De manera correlativa, Podemos obtiene sus peores resultados en esta última comarca.

\section{Abstención:}

Respecto a la participación electoral no se observan diferencias notables entre las comarcas y la ciudad de Valencia. Lo que sí se observa son pequeñas diferencias que no dejan de ser significativas. Dónde la abstención es más baja, con un $26,68 \%$, es en l'Horta Nord, y donde la encontramos más alta es en l'Horta Oest con un 29,92\%. 
Tabla 15: Abstención por comarcas de l’Horta

\begin{tabular}{|c|c|} 
& Abstención \\
\hline Valencia & $27,89 \%$ \\
\hline Horta Nord & $26,68 \%$ \\
\hline Horta Oest & $29,92 \%$ \\
\hline Horta Sud & $28,34 \%$ \\
\hline
\end{tabular}

Fuente: Ministerio del Interior (Elaboración propia)

\section{EL CINTURÓN ROJO.}

No es fácil definir con precisión el ámbito geográfico-político que abarca el denominado cinturón rojo del área metropolitana de Valencia. Se trata un término que ha sido usado fundamentalmente en el ámbito periodístico. A grandes rasgos, este término se refiere a "los municipios próximos a la ciudad de Valencia cuyos votos hayan estado dirigidos a candidaturas de izquierdas, o bien hayan estado regidos por alguno de estos partidos de forma continuada desde las primeras elecciones democráticas". Se consideran de izquierdas a los partidos que se autodefinen como tal y así los percibe la ciudadanía en las encuestas de ubicación ideológica. En nuestro caso, PSPV-PSOE, EUPV (antiguo PCE) y Compromís (Bloc o UPV más Iniciativa). Tras las últimas elecciones debemos incluir también a Podemos o más bien sus candidaturas a las elecciones locales y otros grupos afines que reciben nombres distintos según el municipio.

Desde un punto de vista social, se trata de municipios que en los años 60 y 70 recibieron una fuerte inmigración de zonas del interior, tanto de Valencia como de otras regiones, de personas que buscaban trabajo en la emergente industria de la zona, especialmente en la industria emergente de los sectores del mueble, la automoción, el textil y el juguete. La producción de tipo fordista de aquellos años, aunque en su mayoría se tratase de pequeñas y medianas empresas, contribuyó a formar un grupo social mayoritario de fuerte raigambre obrera, que con la democracia permitió grandes mayorías de izquierda en los municipios de la zona. Esto se fue generalizando desde las primeras elecciones hasta principios de los años 90, incluso tras el triunfo del Partido Popular en la alcaldía de Valencia. Es más, tras la llegada del Partido Popular a la alcaldía de Valencia el término cinturón rojo fue ganando mayor carga simbólica e ideológica en función a la contraposición al gobierno conservador de la capital.

El cinturón rojo como tal se consolidó a partir de las elecciones de 1979 en la década de los ochenta. Para acotar su ámbito y a efectos meramente operativos, tomaremos como referencia desde las primeras elecciones locales en democracia en 1979 hasta las del año 1995, momento en el que se asienta el cambio ideológico en la ciudad de Valencia con una clara mayoría conservadora. Se han establecido unas condiciones necesarias para el cumplimiento para pertenecer al cinturón rojo:

1. Que haya habido un voto mayoritario de izquierdas durante el $85 \%$ de las elecciones a lo largo del periodo de 1979-1995. 
2. Que la izquierda haya formado gobierno durante el $85 \%$ de las legislaturas en el mismo periodo. En el caso en el que hayan dejado de gobernar en una legislatura debido a una moción de censura, se tomará en consideración esa legislatura como gobernada por estos partidos si ha estado en el poder más de la mitad del tiempo de su duración.

3. Que sean localidades con cierta cercanía a Valencia. Las condiciones de movilidad e interrelación entre la ciudad y su hinterland han evolucionado desde 1977 hasta la actualidad, por tanto, no podemos identificar de manera rápida la actual área metropolitana con la percepción tradicional, periodística y ciudadana, de lo que hasta ahora se considera cinturón rojo. Solo se considera cinturón rojo a los municipios que formen parte de las comarcas de l'Horta y reúnan las dos condiciones anteriores.

En la gráfica 5 se muestran los resultados de los partidos de izquierdas en las elecciones del 2015 en los municipios que, en función de estas condiciones, conformarían el Ilamado cinturón rojo. En la mayoría de ellos, el PSPV-PSOE sería el partido de izquierdas más votado. Los casos más destacables serían municipios de tamaño medio como Mislata, Picassent y Picanya. Compromís superaría al PSPV-PSOE en algunos municipios. Los más llamativos, aun con escaso peso poblacional, serían los casos de Beniparrell y Meliana. Estos dos partidos se presentaron y obtuvieron resultados relevantes en todos los municipios del cinturón rojo. En cambio, EUPV y las confluencias de Podemos no presentaron candidaturas en todos los municipios del cinturón.

La presencia o no de ciertos partidos está relacionada sobre todo con el tamaño del municipio. A mayor número de habitantes se genera un mayor número de candidaturas. En el caso de los municipios de la gráfica se observa como los más pequeños, como Llocnou de la Corona, que tiene aproximadamente 133 habitantes, y cuenta solo con dos candidaturas de izquierdas, PSPV-PSOE y Compromís. En cambio, en la localidad de Torrent, que cuenta con unos 80.500 habitantes, presenta las cuatro candidaturas relevantes en estas elecciones de la izquierda, PSPV-PSOE, Compromís, EUPV y Podemos (o asimilados). 
Gráfica 5: Resultado de la izquierda en los diferentes municipios del cinturón rojo en las elecciones locales del 2015

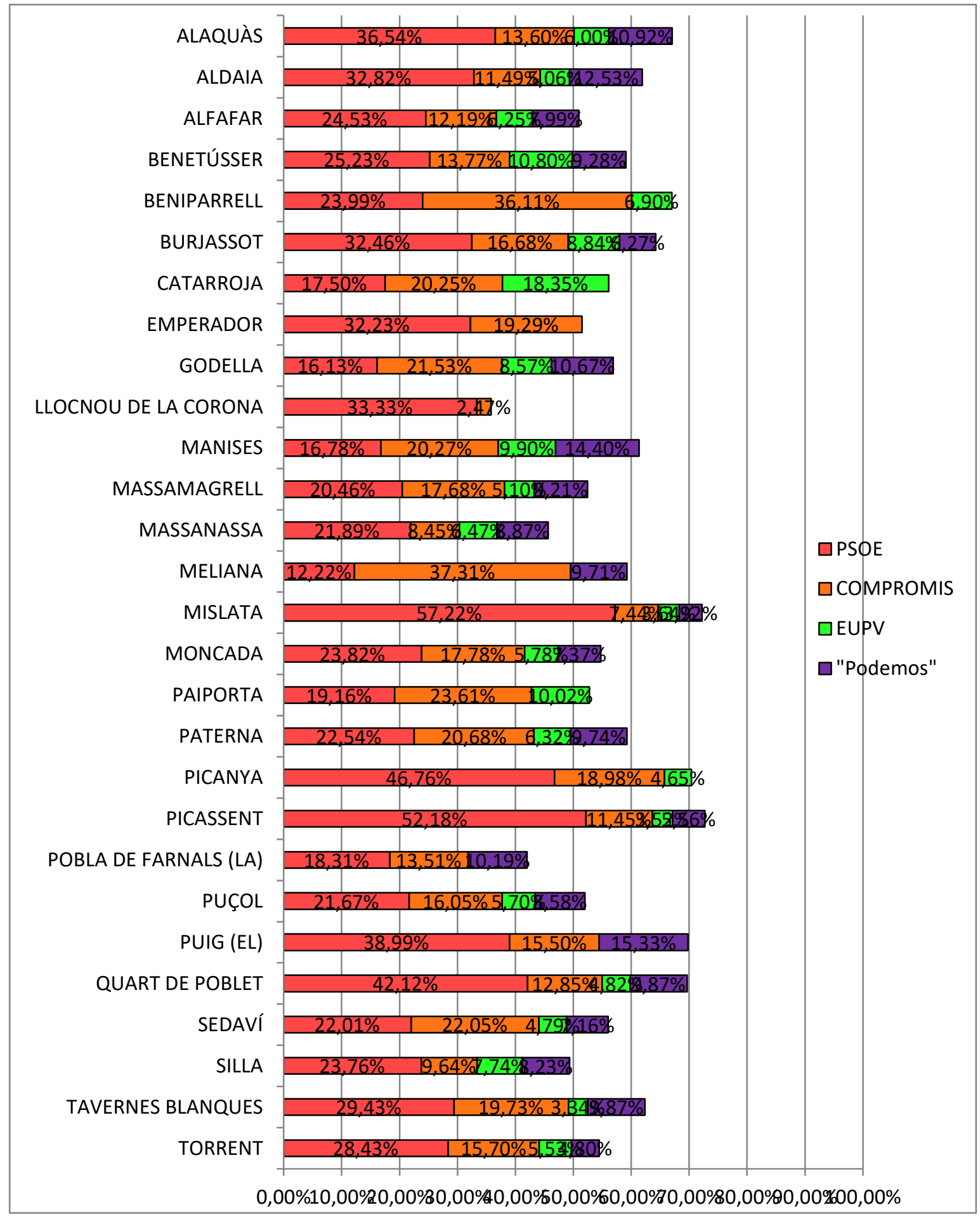

Fuente: Ministerio del Interior (Elaboración propia) 
La tabla 16 nos permite observar la evolución del voto a partidos desde las elecciones de 1999 hasta las de 2015 en el cinturón rojo.

Tabla 16: Resultados de las elecciones locales de 1999, 2003, 2007, 2011 y 2015 en el cinturón rojo de Valencia (número de votos y porcentajes)

\begin{tabular}{|c|c|c|c|c|c|c|}
\hline & & 1999 & 2003 & 2007 & 2011 & 2015 \\
\hline \multirow[t]{2}{*}{ PP } & № & 93.932 & 103.781 & 127.022 & 144.269 & 81.357 \\
\hline & $\%$ & $34,48 \%$ & $35,00 \%$ & $42,75 \%$ & $45,56 \%$ & $24,85 \%$ \\
\hline \multirow[t]{2}{*}{ PSPV-PSOE } & № & 113.919 & 130.295 & 115.032 & 101.089 & 94.997 \\
\hline & $\%$ & $41,82 \%$ & $43,95 \%$ & $38,71 \%$ & $31,92 \%$ & $29,01 \%$ \\
\hline \multirow[t]{2}{*}{ UV } & № & 21.082 & 15.374 & 5890 & & \\
\hline & $\%$ & $7,74 \%$ & $5,19 \%$ & $1,92 \%$ & & \\
\hline \multirow[t]{2}{*}{ EUPV/Entesa } & № & 19.934 & 20.388 & 13.564 & 20.858 & 20.336 \\
\hline & $\%$ & $7,32 \%$ & $6,88 \%$ & $4,56 \%$ & $6,59 \%$ & $6,21 \%$ \\
\hline \multirow[t]{2}{*}{ BLOC/Compromís } & № & 12.079 & 15.344 & 18.709 & 24.939 & 52.869 \\
\hline & $\%$ & $4,43 \%$ & $5,18 \%$ & $6,30 \%$ & $7,88 \%$ & $16,14 \%$ \\
\hline \multirow[t]{2}{*}{ Ciudadanos } & № & & & & & 26.847 \\
\hline & $\%$ & & & & & $8,20 \%$ \\
\hline \multirow[t]{2}{*}{ PODEMOS } & № & & & & & 24.319 \\
\hline & $\%$ & & & & & $7,42 \%$ \\
\hline \multirow[t]{2}{*}{ Otros } & № & 11.479 & 11.256 & 19.927 & 25.477 & 26.649 \\
\hline & $\%$ & $4,21 \%$ & $3,80 \%$ & $5,70 \%$ & $8,05 \%$ & $8,14 \%$ \\
\hline
\end{tabular}

Fuente: Ministerio del Interior (Elaboración propia)

En las elecciones de 1999 y 2003 el PSPV-PSOE fue el partido más votado. En las de 2007 y 2011, sin embargo, pasó a serlo el PP. En las de 2015 el partido más votado ha vuelto a ser el PSPV-PSOE, pero a pesar de ello hay que señalar que ha marcado su peor resultado. Compromís, que mantenía unos discretos resultados en el cinturón, en estas elecciones de 2015 ha experimentado un fuerte incremento en sus apoyos: casi 10 puntos más. Se sitúan como tercera fuerza, algo que ya había ocurrido en las de 2011, pero muy alejado de las dos primeras fuerzas políticas y a muy poca distancia de EUPV. En esta ocasión se sitúa a casi 8 puntos del cuarto que ahora pasa a ser Ciudadanos. Este partido ha irrumpido con fuerza obteniendo un $8,2 \%$ de los votos. El otro partido emergente, Podemos, obtiene el 7,42 \% de los votos, algo menos que Ciudadanos, pero superior que EUPV, que marca en 2007 su peor resultado y en estas elecciones baja unas décimas respectos a las anteriores; a pesar de ello, es el partido que se ha mantenido más o menos estable en todas las elecciones. 
Gráfica 6: Evolución del voto en el cinturón rojo de Valencia

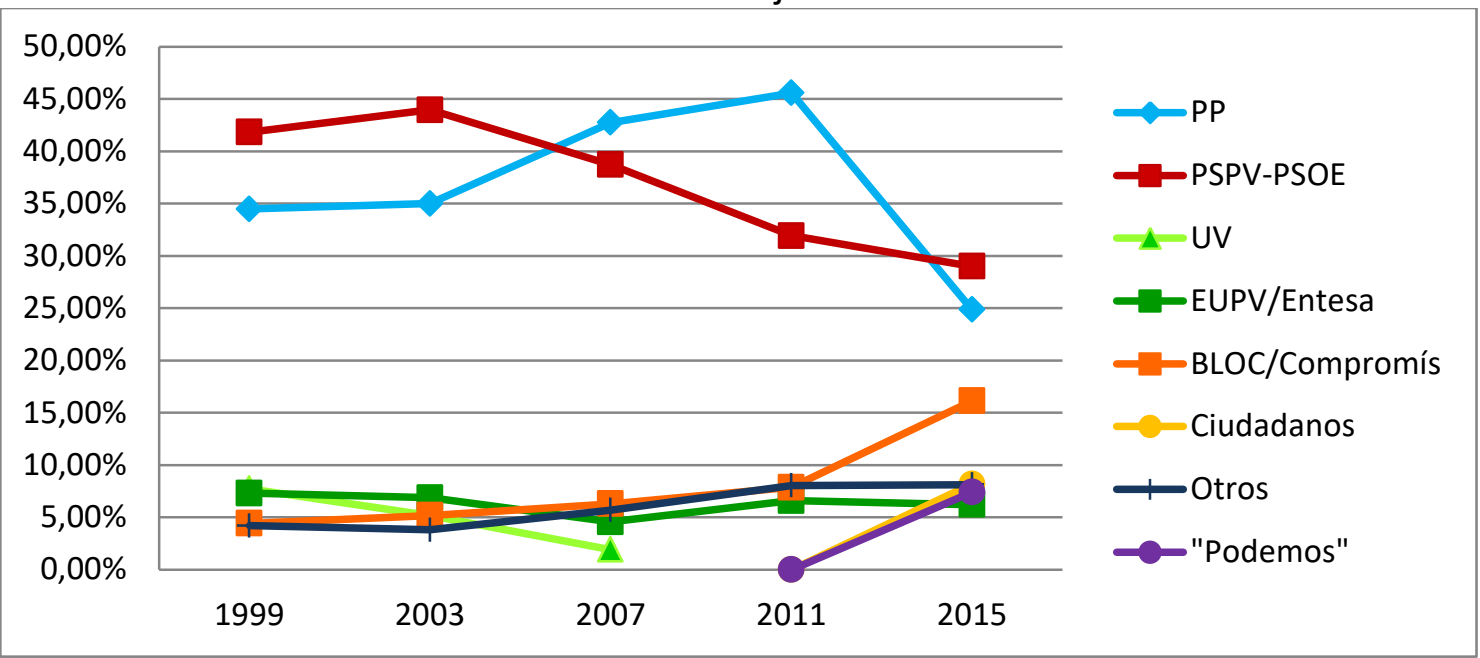

Fuente: Ministerio del Interior (Elaboración propia)

En esta gráfica se aprecia de manera más visual la evolución del voto en el cinturón rojo de Valencia. A grandes rasgos, y como ya hemos comentado, PP y PSPV-PSOE marcan sus peores resultados, a pesar de que siguen siendo los partidos más votados. Se observa como desde 1999 el PP venía incrementando sus apoyos en el cinturón rojo hasta que en 2015 sufre una caída en picado. EI PSPV-PSOE, por su parte, ha pasado de obtener en tono al 40\% de los votos en las elecciones de 1999, 2003 y 2007 a obtener en torno a un 30\% de los votos en las elecciones de 2011 y 2015 si bien la caída en votos es progresiva y no abrupta como en el caso del PP. Estas caídas en votos de las dos principales fuerzas políticas se corresponden en 2015 con el fuerte incremento en votos de las tres fuerzas emergentes: Compromís, Ciudadanos y las confluencias de Podemos. Hay que resaltar una vez más que es EU en este cinturón donde mantiene sus apoyos tradicionales obteniendo incluso mejores resultados en términos porcentuales que en algunos comicios anteriores como los de 2007 y prácticamente idénticos a los de 2003 o 2011.

\section{CONCLUSIONES.}

Las elecciones del 2015 han supuesto un cambio de tendencia en el comportamiento electoral de los ciudadanos del área metropolitana de Valencia.

Los partidos tradicionales, Partido Popular y PSPV-PSOE, han perdido muchos de los apoyos con los que han contado tradicionalmente. El primero ha sido el partido que más ha perdido no sólo en términos electorales sino también y especialmente en términos de poder institucional. Hay que tener en cuenta que veníamos de unos años con sólidas mayorías, y una bajada tan significativa ha supuesto la pérdida de buena parte de las alcaldías que ostentaban. Respecto al PSPV-PSOE, hay que decir que ha marcado los peores resultados de su historia. No obstante, salvo en la ciudad de Valencia, se mantiene como segunda fuerza política (en alguna comarca como l'Horta Oest es la primera) y, como hemos visto, ha conseguido gran número de alcaldías, en solitario o con el apoyo de otras fuerzas políticas como Compromís, EUPV o las confluencias de Podemos. A pesar de 
esto, PP y PSPV-PSOE siguen siendo los dos partidos más votados en el conjunto del área metropolitana.

Han aparecido partidos nuevos, como Ciudadanos o Podemos y sus afines. Otros como Compromís han salido muy reforzados. Todos ellos han logrado sus mejores resultados en la ciudad de Valencia. La mayor subida en estas elecciones la ha experimentado Compromís, partido que se sitúa en algunos grandes municipios, incluso en la ciudad de Valencia, como segunda fuerza, muy cerca del Partido Popular. Esto les ha permitido formar gobiernos, apoyando al PSPV-PSOE o bien accediendo a la alcaldía, con la ayuda de otras fuerzas de izquierdas. Significativa ha sido también la fuerte irrupción de Ciudadanos: se han situado en muchas localidades como tercera fuerza, aunque no ha conseguido alcaldías, si bien ha participado en la conformación de gobiernos en algunos municipios del área. La irrupción de Podemos también es significativa, especialmente en la ciudad de Valencia. Ha conseguido la alcaldía en Villar del Arzobispo y han participado en la conformación de un buen número de gobiernos municipales de izquierda. EUPV, aunque su porcentaje de apoyos en el área metropolitana apenas supera el 5\%, ha mantenido sus apoyos en el área especialmente en el cinturón rojo, y también ha contribuido a la conformación de algún gobierno municipal.

Hemos podido comprobar que existe relación con el número de habitantes y los partidos existentes en los municipios, o los que tienen mayor fuerza. Se observa como en los municipios con menor número de habitantes, se vota en mayor medida a partidos tradicionales (PP, PSPV-PSOE), posiblemente derivado de la menor oferta de partidos. Por el contrario, se ha constatado como en los municipios con mayor número de habitantes, y en Valencia capital, los partidos tradicionales pierden peso a favor de las otras alternativas emergentes como Compromís, Ciudadanos o Podemos.

Respecto a la relación existente entre las comarcas de l’Horta y los partidos son significativos algunos aspectos. En primer lugar, el Partido Popular tiene más o menos la misma fuerza tanto en Valencia, como en I'Horta Nord; y es ligeramente inferior en I'Horta Oest y algo superior en I'Horta Sud. En segundo lugar, el PSPV-PSOE en Valencia cuenta con poca fuerza comparado con el resto de comarcas. En l'Horta Nord y l'Horta Sud tiene aproximadamente el mismo apoyo, y en l'Horta Oest es dónde más fuerza posee. En tercer lugar, Compromís en Valencia ciudad ha tenido sus mejores resultados, también en I'Horta Nord, quizá no tanto en l'Horta Oest y l'Horta Sud. En cuarto lugar, Ciudadanos también tiene sus mejores resultados en la ciudad de Valencia, a considerable distancia del resto de comarcas. En quinto lugar, EUPV, si bien ha perdido su representación en el ayuntamiento de la ciudad de Valencia, ha mantenido en general sus apoyos, especialmente en l'Horta Sud.

El caso del cinturón rojo alrededor de la ciudad de Valencia es muy llamativo, ya que la izquierda ha vuelto a salir reforzada tras las elecciones de los años 2007 y 2011 en las que había dejado de ser la fuerza predominante, desmintiendo al título que recibía. En las elecciones locales de 2015 la izquierda ha recuperado la fortaleza en términos de apoyo electoral y, sobre todo, el poder en los municipios que forman parte del cinturón. Eso sí, los gobiernos que se han conformado en el cinturón son generalmente de coalición ya que en pocos sitios los partidos han conseguido apoyos suficientes para gobernar en 
solitario. De esta forma, podemos hablar de la reaparición del cinturón rojo de Valencia, caracterizado ahora por unas variadas tonalidades de color rojo.

Respecto al sistema de partidos en general del área metropolitana, se ha producido un cambio en su conformación. Desde hace unos años, hasta las pasadas elecciones locales, el Partido Popular mantenía una posición predominante y cuasi hegemónica. En estos últimos comicios hemos pasado a un sistema de partidos que podemos calificar de pluralismo moderado, siendo que, además, dependiendo de municipios concretos se presentan diferentes variables a la hora de poder conformar un gobierno.

A grandes rasgos, y como conclusión final, podemos decir que, tras estas últimas elecciones locales, el escenario político ha cambiado de manera significativa. En el área metropolitana de Valencia, como en otras zonas de España -especialmente, las urbanasha salido muy debilitado el bipartidismo conformado en anterior comicios por PP y PSPVPSOE, manteniendo EU en gran medida sus apoyos tradicionales; $y$, a su vez, han ido ganando fuerza partidos emergentes $u$ otros que hasta el momento se consideraban minoritarios como Compromís, Ciudadanos o Podemos.

\section{BIBLIOGRAFÍA Y FUENTES DOCUMENTALES}

Franch i Ferrer, V. y Martín Cubas, J. (2000): "Eleccions, partits i Sistema de partits" en NINYOLES, R. (ed.) La societat valenciana: estructura social i institucional, Alzira, Bromera.

Martin Cubas, J.; Escribano García, C.; y Jiménez Lázaro, J. y Ramis García, S.J. (2011): “El comportamiento electoral en las elecciones locales del área metropolitana de Valencia: las elecciones de 2011 y la volatilización del «cinturón rojo» de Valencia", Cuadernos Constitucionales de la Cátedra Fadrique Furió Ceriol: 75/76.

Martín Cubas, J. (2015): "La ruptura de un ciclo electoral en la Comunidad Valenciana: estudio comparado de los resultados de las elecciones locales y autonómicas de 2015 en la Comunidad Valenciana", Participació electoral y territorio. Análisis de les eleccions municipals i autonómiques 2015. Valencia, Universidad de Valencia.

Martín Cubas, J. (2007): "Los espacios de competencia electoral en la Comunidad Valenciana (1995-2005)", Cuadernos constitucionales de la Cátedra Fadrique Furió Ceriol, no 60/61.

Martínez De Lejarza, J. e Martinez De Lejarza, I.M. (2002): “Delimitación de áreas metropolitanas mediante un modelo anisópotro de decrecimiento exponencial. Una aplicación al caso del área metropolitana de Valencia", Estudios de Economía Aplicada: 2072.

Ministerio de Interior, Gobierno de España, Información electoral: http://www.interior.gob.es/informacion-electoral

Presidencia de la Generalitat Valenciana, Portal de información ARGOS, Generalitat Valencian: http://www.argos.gva.es/es/electoral/ 